\title{
Study on Competitive Strategy of China Railway Express Operation by Land Port Company
}

\author{
Wenjun Sun* \\ School of Economics and Management, Shaanxi University of Science and Technology, Xi'an, China \\ Email: *swj_0820@163.com
}

How to cite this paper: Sun, W. J. (2020). Study on Competitive Strategy of China Railway Express Operation by Land Port Company. American Journal of Industrial and Business Management, 10, 711-722. https://doi.org/10.4236/ajibm.2020.104048

Received: March 15, 2020

Accepted: April 6, 2020

Published: April 9, 2020

Copyright $\odot 2020$ by author(s) and Scientific Research Publishing Inc. This work is licensed under the Creative Commons Attribution International License (CC BY 4.0).

http://creativecommons.org/licenses/by/4.0/

\begin{abstract}
With the in-depth implementation of the "One Belt One Road" initiative, the number of cities, which have opened direct train to European countries, is increasing in China. With the rapid development of China Railway Express (CR Express) market, the problems of insufficient supply, disorderly competition and high operation cost are becoming more and more prominent, which leads to increasingly disordered competition among CR Express. Finding a balanced subsidy among local governments is a key way to solve the above problems. This paper constructs a Hotelling model which is in line with the characteristics of the development of CR Express from the aspects of consignor's utility and land port company's revenue. Then the equilibrium price, market share and revenue of land port company are solved, and the optimal local government subsidy under equilibrium condition is analyzed. Subsequently, the land port company (Xi'an) and land port company (Zhengzhou) are chosen for empirical analysis. The establishment of government subsidy policies conducive to market development can effectively reduce the disordered competition among land port companies and contribute to the sustainable development of CR Express.
\end{abstract}

\section{Keywords}

China Railway Express, Land Port Company, Competitive Strategy, Hotelling Model, Balanced Subsidy

\section{Introduction}

With the in-depth implementation of the "One Belt and One Road" (B \& R) initiative, the economic and trade development of inland cities has been developing well. China Railway Express (CR Express), as a new way of freight transportation, is running between China and Europe and the countries along the B \& R. 
It quickly became an important carrier of economic and trade cooperation between China and European countries. After $\mathrm{Yu}$ Xin $\mathrm{Ou}$ between Chongqing and Duisburg of Germany was operated in 2011, as of October 2019, the number of CR Express had already accumulated to 20000 (http://www.chinanews.com/). China had formed train networks composed of 65 domestic routes and 65 origin cities for operating direct train. CR Express passes through the inland exit ports of Alashankou, Erlianhot, and Manzhouli along the three main railway corridors (the western, central, and eastern corridors), and reaches 56 cities in 17 countries in Europe. During the operation of the CR Express service, the train service company acts as a platform, and is mainly established by the origin cities. For example, the operating platform of the "Zhengxinou" line is "Zhengzhou Lugang International Development and Construction Co., Ltd.”, the company was established on June 27, 2013 and is mainly engaged in customs clearance, cross-border trade and e-commerce; Xi'an "Chang an hao" line operation platform company is "Xi' an International Land Port Investment Development Group Co., Ltd.", the company was established in June 2009, and its business involves various fields such as port operations and logistics, international trade, production and living facilities, investment and financial services; Chongqing's "Yuxinou" line operation platform company is "Yuxinou Logistics Co., Ltd.", this company was established on April 12, 2012. It mainly provides two-way "station-to-station" services between Chongqing and European countries, and so on. Different types of CR Express enterprise in different origin city. Whether it is a state-owned enterprise, a private enterprise, or a local government-led model, the train operating companies are collectively referred to as "land port company" in this paper. For CR Express, which is still in the early stages of development, although the transportation scale of CR Express continues to expand, the phenomenon of low full load ratio still exists. In order to absorb more cargoes in the fiercely competitive market, land port companies have successively reduced prices to expand market share rate, thereby increasing its own profits. However, most of the revenue of land port companies comes from local government subsidies. In the long run, the government's excessive subsidies will interfere the orderly development of the market, and thus limited the independent ability to absorb cargo for land port company. Especially the "Zheng Xin ou" train, it has the largest marketing efforts at present, and proposes free pickup of cargo within 1500 kilometers of highways, which seriously affects the existing market order in the eastern region. In order to solve the problems of insufficient supply and disorderly competition for CR Express, based on the game theory, this paper analyzes and obtains the effective government subsidy scheme when the profit of the land port company is maximized. And from the perspective of the intensity of the distribution of the originating cities and the strength of the subsidies, land port company (Xi'an) and land port company (Zhengzhou) located in the central and western regions of China were selected as the object of empirical analysis in this paper, so as to provide the corresponding business strategy for the land port company. 
Our research makes two contributions to the study. 1) In view of the abnormal development of CR Express market, we construct a Hotelling model to meet the characteristics of CR Express. Through the analysis of the relationship among the main stakeholders, such as land port companies, consignors and local governments, the subsidy policies to meet the market-oriented development are obtained. 2) In the Hotelling model construction, we consider government subsidies in both the land port company's revenue and the consignor's utility function to comprehensively analyze the equilibrium subsidies of the local government when the consignor's utility and the land port company's revenue are maximized, thereby studying the problem of unordered competition for CR Express.

\section{Literature Review}

\subsection{Operational Performance of CR Express}

The continuous enrichment of trade channels and modes between China and the European countries has brought rare development opportunities to the CR Express. Most scholars analyze the advantages and problems of CR Express in the development from a qualitative perspective, and make an in-depth analysis of its basic operation and layout (Wang, 2018; Zhao et al., 2018). Yang et al. (2018) improved the operation of the New Asia-Europe Bridge Railway and Budapest Railway by building a bi-level programming model aimed at optimizing the shipping network between Asia and Europe. Wang (2015) analyzed the advantages and disadvantages of different transportation modes, such as sea transportation and railway transportation, and qualitatively sorted out the comparative advantages of high punctuality rate and strong safety for CR Express. Comparing with the advantages of CR Express, the existing problems still cannot be underestimated. He (2016) qualitatively examined the key factors that influence smooth railway transportation in the Silk Road Economic Belt, and proposed solutions. $\mathrm{Ma}$ (2018) qualitatively analyzed the problems such as unclear market positioning, insufficient supporting facilities, fierce price competition and serious train congestion. At present, local government subsidies have almost become the prerequisite for operation of CR Express, which has created a good environment for the sustainable development of CR Express. Each train operation enterprise adopts various preferential policies to absorb the cargoes. Among them, government financial subsidies are the most common, thereby leading to the financial damage of the government (Zhang, 2018b). However, throughout the literature, researchers mainly focused on the status quo for operating CR Express, operational problems, and corresponding strategies to improve train transport between China and Europe.

\subsection{Application of Hotelling Model}

Hotelling model is mainly used in the competition among multi-agent with product difference, and the application of classic Hotelling model for spatial dif- 
ference is very extensive. Le et al. (2018) based on the competition of multiple ports, used Hotelling model to analyze the competition relationship between ports in terms of price, revenue and other aspects of iron ore business. Based on the differentiated network effects, the Hotelling model was used to analyze the pricing and strategy choices of oligopolies, and its application in this field was promoted (Wang et al., 2016). Xu and Zhu (2007) introduced network externalities into the Hotelling model under linear transportation costs, and studied the location and price competition of two network product manufacturers to analyze the effects of network externalities on them. In research on the influencing factors of price competition among CR Express companies, Zhang (2018a) believed that network externalities have an impact on the satisfaction of shippers in obtaining services, and government subsidies only affect the revenue of train companies. Therefore, she researched on the equilibrium prices and equilibrium incomes of the train companies using the Hotelling model. However, it is not found that government subsidies are considered in the function of both shipper and the land port company's income, so as to analyze the problem of disorderly competition in the operation of CR Express.

To sum up, in the study of the equilibrium strategy of the Hotelling price competition model, scholars are more likely to analyze the price competition with network externalities and product differences to find the equilibrium conditions that affect the pricing and location of enterprises. However, there are relatively few studies using this model on CR Express. Among them, there is a lack of research on the impact of government subsidy on the operation of train companies from multiple perspectives.

\section{Construction and Solution of Hotelling Model Considering Government Subsidy}

\subsection{Model Hypothesis and Variable Definition}

1) Model hypothesis

Hypothesis 1: consignors are evenly distributed in $[0,1]$, and the transportation cost from the source to the departure station of CR Express is a linear function. Considering the independence of the consignor, the consignor's demand for container is accounted for as a single 40 foot's container. Consignor's basic utility $U_{0}$ is large enough that the market can be completely covered.

Hypothesis 2: in the region $[0,1]$, there are two land port companies providing services, i.e. land port company 1 and land port company 2 . They are distributed in $a$ and $b$ respectively. Without losing generality, it is set as $0 \leq a<b \leq 1$.

2) variable definition

The variables involved in the model construction of this paper are described in Table 1.

\subsection{Model Building}

As the decision-making body in the operation of CR Express market, land port 
Table 1. Symbolic explanation.

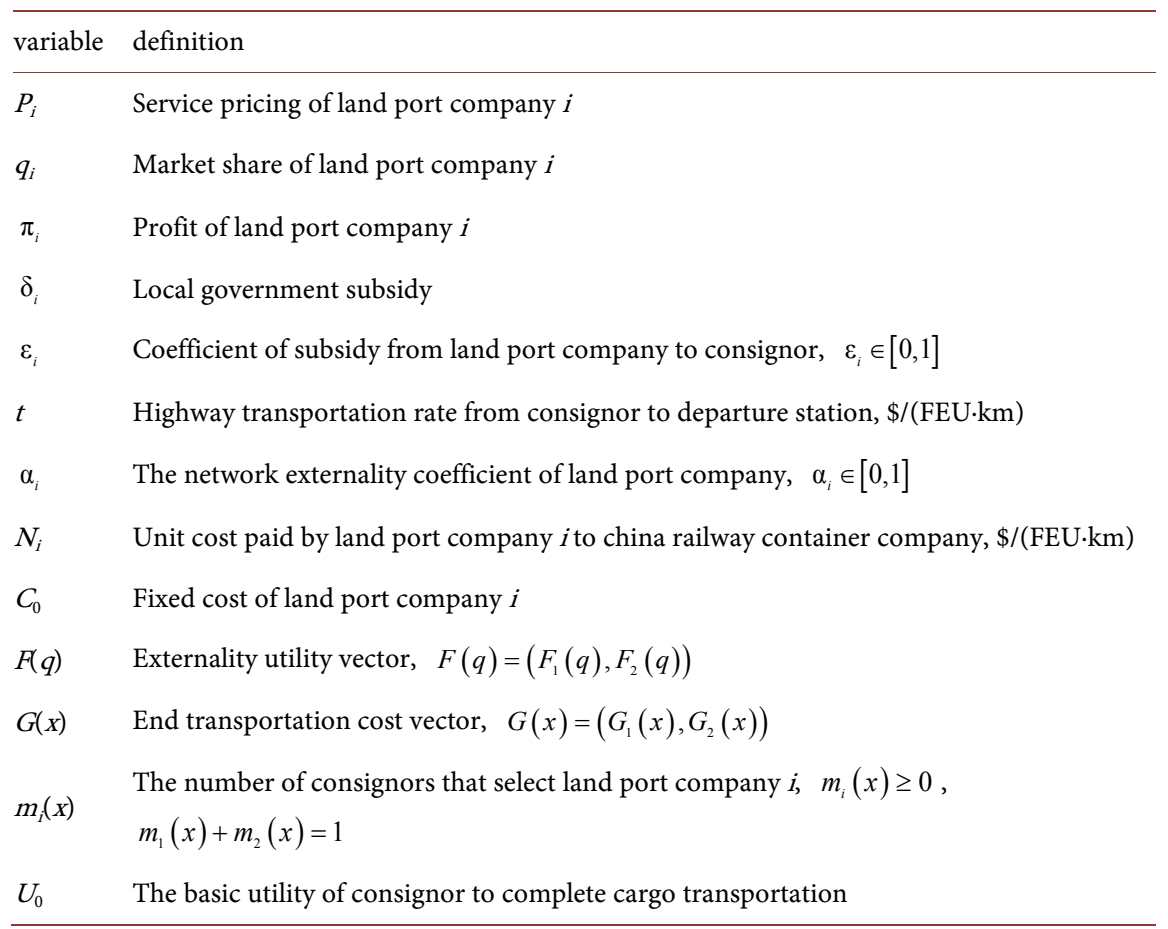

Note: $i=1,2$, it represents land port company 1 and land port 2 respectively.

company and consignor can influence each other. Consignor's choice of land port company directly affects the revenue of land port company. The preferential subsidies provided by the land port company for the consignor also directly affect the effectiveness of the consignor, thereby affecting the selection of the consignor.

1) Consignor utility

According to the principle of utility maximization of rational consignors, the consignor's choice of land port company is to meet the personal interest maximization in this paper. There are many factors that consignors will consider when choosing a land port company for service, such as, whether it has attractive service price, quality of service provided by land port company and other relevant preferential strategies. Therefore, the cost, timeliness and profit are three key factors in the consignor utility. The consignor utility function is as follows:

$$
\begin{aligned}
& U_{1}(x)=U_{0}+\alpha_{1} q_{1}-|x-a| t-p_{1}+\varepsilon_{1} \delta_{1} q_{1} \\
& U_{2}(x)=U_{0}+\alpha_{2} q_{2}-|x-b| t-p_{2}+\varepsilon_{2} \delta_{2} q_{2}
\end{aligned}
$$

$U_{0}$ is the basic utility of consignor to complete cargo transportation; $\alpha_{i} q_{i}$ represents the network externality utility obtained by the consignor; $(x-a) t$ and $(x-b) t$ are terminal cargo transportation expenses of consignor to land port company respectively; $p_{i}$ is the service pricing provided by the land port company; $\varepsilon_{i} \delta_{i} q_{i}$ is the effect of government indirect subsidy enjoyed by consignor. Consignors need to compare the effectiveness of two land port companies to themselves, and then choose the land port company that they want to cooperate 
with.

2) Division of market share of land port company

In this paper, the problem of consignor's choice of land port company is transformed into the problem of traveler's choice of road in transportation network (i.e., travelers choose the road according to the principle of cost minimization). We use the method of variational inequality to analyze the market share of land port company (Zhu et al., 2014). The variational inequality is as follows:

$$
\left\langle p-U_{0}-F(q)+G(x)+T(q), m(x)-y\right\rangle \leq 0, \quad \forall y \in \Omega(x)
$$

Among them, \langle\rangle is the inner product vector, $P$ is the price vector of train service provided by land port company, recorded as $P\left(p_{1}, p_{2}\right) . F(q)$ is the network externality vector of CR Express service, $G(q)$ is the end transportation cost vector, $T(q)$ is the indirect subsidy cost vector, the details are as follows:

$$
\begin{gathered}
F(q)=\left(\alpha_{1} \int_{0}^{1} m_{1}(x) \mathrm{d} x, \alpha_{2} \int_{0}^{1} m_{2}(x) \mathrm{d} x\right) \\
G(x)=(|x-a| t,|x-b| t) \\
T(q)=\left(\varepsilon_{1} \delta_{1} q_{1}, \varepsilon_{2} \delta_{2} q_{2}\right) \\
m(x)=\left(m_{1}(x), m_{2}(x)\right)
\end{gathered}
$$

According to formula (3) - (7) and $m_{1}(x)+m_{2}(x)=1$, the variational inequality is transformed into:

$$
\begin{aligned}
& \left\langle p_{1}-p_{2}-\left(\alpha_{1}+\alpha_{2}\right) q_{1}+\alpha_{2}+(|x-a|-|x-b|) t\right. \\
& \left.+\left(\varepsilon_{1} \delta_{1}+\varepsilon_{2} \delta_{2}\right) q_{1}-\varepsilon_{2} \delta_{2}, m_{1}(x)-y_{1}(x)\right\rangle \leq 0, \quad \forall y \in \Omega(x)
\end{aligned}
$$

When the location, transportation service price, network externalities, government subsidies and other factors of the land port company have been determined, formula (8) must have corresponding market division. According to the actual situation, the following condition should be met when the two land port companies jointly occupy the market:

$$
-\alpha_{2}+(b-a) t+\varepsilon_{2} \delta_{2}<p_{1}-p_{2}<\alpha_{1}-(b-a) t-\varepsilon_{1} \delta_{1}
$$

3) Profit of land port company

As the main operating body of train service, the profit of land port company is affected by many factors. It mainly includes the transportation fees charged to the consignor, fees paid to china railway container company, subsidies from local governments, fixed costs incurred by inland port company's own construction. The revenue function is expressed as follows:

$$
\begin{aligned}
& \pi_{1}=p_{1} q_{1}-N_{1} q_{1}+\left(1-\varepsilon_{1}\right) \delta_{1} q_{1}-C_{0} \\
& \pi_{2}=p_{2} q_{2}-N_{2} q_{2}+\left(1-\varepsilon_{2}\right) \delta_{2} q_{2}-C_{0}
\end{aligned}
$$

\subsection{Model Solution}

When the two companies share the market, there is indifference point $\theta$. 


$$
m_{1}(x)=\left\{\begin{array}{l}
1, x \in[0, \theta] \\
0, x \in[\theta, 1]
\end{array}, \quad q_{1}=\int_{0}^{1} m_{1}(x) \mathrm{d} x=\int_{0}^{\theta} 1 \mathrm{~d} x=\theta\right.
$$

Therefore, from formula (8), we can get $\theta=\frac{p_{2}-p_{1}-\alpha_{2}+\varepsilon_{2} \delta_{2}+(a+b) t}{2 t+\varepsilon_{1} \delta_{1}+\varepsilon_{2} \delta_{2}-\alpha_{1}-\alpha_{2}}$. The equilibrium market shares of land port companies are as follows:

$$
\begin{gathered}
q_{1}\left(p_{1}, p_{2}\right)=\frac{p_{2}-p_{1}-\alpha_{2}+\varepsilon_{2} \delta_{2}+(a+b) t}{2 t+\varepsilon_{1} \delta_{1}+\varepsilon_{2} \delta_{2}-\alpha_{1}-\alpha_{2}} \\
q_{2}\left(p_{1}, p_{2}\right)=\frac{p_{1}-p_{2}-\alpha_{1}+\varepsilon_{1} \delta_{1}+(2-a-b) t}{2 t+\varepsilon_{1} \delta_{1}+\varepsilon_{2} \delta_{2}-\alpha_{1}-\alpha_{2}}
\end{gathered}
$$

At this time, the revenue function of land port company 1 and land port company 2 when they share the market is further transformed into:

$$
\begin{gathered}
\pi_{1}\left(p_{1}, p_{2}\right)=\left[p_{1}-N_{1}+\left(1-\varepsilon_{1}\right) \delta_{1}\right] \cdot \frac{p_{2}-p_{1}-\alpha_{2}+\varepsilon_{2} \delta_{2}+(a+b) t}{2 t+\varepsilon_{1} \delta_{1}+\varepsilon_{2} \delta_{2}-\alpha_{1}-\alpha_{2}}-C_{0} \\
\pi_{2}\left(p_{1}, p_{2}\right)=\left[p_{2}-N_{2}+\left(1-\varepsilon_{2}\right) \delta_{2}\right] \cdot \frac{p_{1}-p_{2}-\alpha_{1}+\varepsilon_{1} \delta_{1}+(2-a-b) t}{2 t+\varepsilon_{1} \delta_{1}+\varepsilon_{2} \delta_{2}-\alpha_{1}-\alpha_{2}}-C_{0}
\end{gathered}
$$

Then we get equilibrium price $p^{*}$, equilibrium market share $q^{*}$, equilibrium profit $\pi^{*}$ :

$$
\begin{gathered}
p_{1}^{*}=\frac{-\left(\alpha_{1}+2 \alpha_{2}\right)+N_{2}+2 N_{1}+(2+a+b) t+\left(3 \varepsilon_{1}-2\right) \delta_{1}+\left(3 \varepsilon_{2}-1\right) \delta_{2}}{3} \\
p_{2}^{*}=\frac{-\left(2 \alpha_{1}+\alpha_{2}\right)+N_{1}+2 N_{2}+(4-a-b) t+\left(3 \varepsilon_{1}-1\right) \delta_{1}+\left(3 \varepsilon_{2}-2\right) \delta_{2}}{3} \\
q_{1}^{*}=\frac{-2 \alpha_{2}-\alpha_{1}-N_{1}+N_{2}+(2+a+b) t+\delta_{1}+\left(3 \varepsilon_{2}-1\right) \delta_{2}}{3\left(2 t+\varepsilon_{1} \delta_{1}+\varepsilon_{2} \delta_{2}-\alpha_{1}-\alpha_{2}\right)} \\
q_{2}^{*}=\frac{-2 \alpha_{1}-\alpha_{2}+N_{1}-N_{2}+(4-a-b) t+\left(3 \varepsilon_{1}-1\right) \delta_{1}+\delta_{2}}{3\left(2 t+\varepsilon_{1} \delta_{1}+\varepsilon_{2} \delta_{2}-\alpha_{1}-\alpha_{2}\right)} \\
\pi_{1}^{*}=\frac{\left[\alpha_{1}+2 \alpha_{2}+N_{1}-N_{2}-(2+a+b) t-\delta_{1}-\left(3 \varepsilon_{2}-1\right) \delta_{2}\right]^{2}}{9\left(2 t+\varepsilon_{1} \delta_{1}+\varepsilon_{2} \delta_{2}-\alpha_{1}-\alpha_{2}\right)}-C_{0} \\
\pi_{2}^{*}=\frac{\left[2 \alpha_{1}+\alpha_{2}-N_{1}+N_{2}-(4-a-b) t-\left(3 \varepsilon_{1}-1\right) \delta_{1}-\delta_{2}\right]^{2}}{9\left(2 t+\varepsilon_{1} \delta_{1}+\varepsilon_{2} \delta_{2}-\alpha_{1}-\alpha_{2}\right)}-C_{0}
\end{gathered}
$$

\section{Empirical Analysis}

This paper chooses the land port company (Xi'an) and the land port company (Zhengzhou) for empirical analysis. We will compare the balanced subsidy with the local government subsidy obtained in the actual operation of inland port company, and then get the government balanced subsidy which is suitable for the market development.

\subsection{Determination of Variable Parameters}

1) Value of location $a$ and $b$ for two land port companies 
Considering the fact that Xi'an is in the west of Zhengzhou, set the land port company (Xi'an) as the left node a in the region, and the land port company (Zhengzhou) as the right node $b$ in the region. According to the actual farthest cargo collection range of land port company, $1500 \mathrm{~km}$ is taken as the cargo collection radius of land port company (Zhengzhou) in this paper. Among all the cargo collection cities in Xi'an, Shenzhen is the farthest, with a transportation distance of about $1700 \mathrm{~km}$. Therefore, $1700 \mathrm{~km}$ is taken as the cargo collection radius of the land port company (Xi'an). Taking into account the economy and timeliness of operation for CR Express, we measure the distance between two land port companies, i.e. $d=495.4 \mathrm{~km}$. The final value of the land port company's location is shown respectively: $a=(1500-495.4) /(3200-495.4) \approx 0.4$; $b=1500 /(3200-495.4) \approx 0.6$.

2) Network externality coefficient $-\alpha_{i}$

In the operation process of CR Express, the frequency of operation, the completeness of the station infrastructure, and the service quality of the land port company affect the consignor's choice. For the CR Express, which is still in the early stage of development, the service level gap of each land port company is relatively small, and the infrastructure of each station is being improved. Therefore, the network externalities of land port company are considered in the optimal state in this paper, i.e., $\alpha_{i}=1$.

3) Unit transportation cost of CR Express- $N_{i}$

At present, the fees paid by land port company to china railway container company adopt the way of quantity price bundling. The specific cost is: base price 1 (i.e., departure and arrival service charge of container cargo transportation) + base price 2 (i.e., transportation base price) $\times$ operation distance. Among them, base price 1 is about $98 \$ / F E U$, base price 2 is about $0.4 \$ / F E U \cdot k m$. (Data from national policy documents).Considering CR Express reaches European countries through Moscow of Russia, we take "Xi' an (or Zhengzhou)-Alashankou-Moscow" as the transportation route selected in this paper (Li et al., 2019). Therefore, the railway transportation fee paid by the land port company (Xi'an) to china railway container company is $98+0.4 \times(3024+4093)=2944.8 \$ / F E U$, and the land port company (Zhengzhou) is $98+0.4 \times(3535+4093)=3149.2 \$ / F E U$.

4) Consignor's terminal transportation rate $-t$

In general, domestic consignors often choose the way of highway transportation to transport the cargo to the departure center station of CR Express. According to lucky logistics network (http://www.haoyun56.com/), the unit cost of highway transportation is about $0.35 \$ / \mathrm{FEU} \cdot \mathrm{km}$, and we regard it as the indicator value of the consignor's transportation rate.

5) Fixed costs incurred in the operation of CR Express- $C_{0}$

Considering that the fixed cost includes various factors such as infrastructure construction cost and labor cost of each station, and their contribution to this study is relatively weak, therefore, the fixed cost of the two land port companies is regarded as equal and constant. 


\subsection{Discussion of Relevant Results}

1) Discussion on the influence of government subsidy on the equilibrium price of land port company

Put the values of parameters of land port company (Xi'an) and land port company (Zhengzhou) into $p_{1}^{*}$ and $p_{2}^{*}$ respectively. According to the first-order partial derivative of equilibrium price-related government subsidy: when the subsidy coefficient provided by the land port company to the consignor is less than two-thirds (i.e., $0<\varepsilon_{i}<2 / 3$ ), there is a reverse relationship between equilibrium price and government subsidy of inland port company. On the contrary, when $2 / 3<\varepsilon_{i}<1$, the equilibrium price of land port company is positively correlated with government subsidy.

2) Discussion on the influence of government subsidy on the equilibrium share of land port company

Put the values of parameters of land port company (Xi'an) and land port company (Zhengzhou) into $q_{1}^{*}$ and $q_{2}^{*}$ respectively. The first-order partial derivative of equilibrium share related government subsidy is as follows:

$$
\begin{gathered}
\frac{\partial q_{1}^{*}}{\partial \delta_{1}}=\frac{-202.45 \varepsilon_{1}+\left(\varepsilon_{2}-3 \varepsilon_{1} \varepsilon_{2}+\varepsilon_{1}\right) \delta_{2}-1.3}{3\left(\varepsilon_{1} \delta_{1}+\varepsilon_{2} \delta_{2}-1.3\right)^{2}} \\
\frac{\partial q_{2}^{*}}{\partial \delta_{2}}=\frac{206.35 \varepsilon_{2}+\left(\varepsilon_{1}-3 \varepsilon_{1} \varepsilon_{2}+\varepsilon_{2}\right) \delta_{1}-1.3}{3\left(\varepsilon_{1} \delta_{1}+\varepsilon_{2} \delta_{2}-1.3\right)^{2}}
\end{gathered}
$$

It can be seen from formulas (22) and (23) that the positive and negative relationship between government subsidy and market share of land port company mainly depends on the numerator. When $\delta_{2}<101.225 \varepsilon_{2}+0.65$, there is $\partial q_{1}^{*} / \partial \delta_{1}<0$, at this time, the market share of land port company (Xi'an) will decrease with the increase of local government subsidy. Similarly, when $206.35 \varepsilon_{2}-1.3 / 3<\delta_{1}<1.3-206.35 \varepsilon_{2} / 2$, there is $\partial q_{2}^{*} / \partial \delta_{2}<0$, the equilibrium market share of the land port company (Zhengzhou) is in reverse relation to the local government subsidy, that is, the more government subsidies, the less market share. When $1.3-206.35 \varepsilon_{2} / 2<\delta_{1}<206.35 \varepsilon_{2}-1.3 / 3$, there is $\partial q_{2}^{*} / \partial \delta_{2}>0$, the equilibrium market share of the land port company (Zhengzhou) is in positive relation to the local government subsidy, that is, the more government subsidies, the more market share.

3) Discussion on the influence of government subsidy on the equilibrium profit of land port company

Put the values of parameters of land port company (Xi'an) and land port company (Zhengzhou) into $\pi_{1}^{*}$ and $\pi_{2}^{*}$ respectively. The first-order partial derivative of equilibrium profit-related government subsidy is as follows:

$$
\begin{aligned}
& \frac{\partial \pi_{1}^{*}}{\partial \delta_{1}}=\frac{-\varepsilon_{1} \delta_{1}^{2}+\left(2 \varepsilon_{2} \delta_{2}-2.6\right) \delta_{1}-\left[202.45+\left(3 \varepsilon_{1}-1\right) \delta_{2}\right] \cdot\left[2.6-2 \varepsilon_{2}-204.35 \varepsilon_{1}+\left(3 \varepsilon_{1} \varepsilon_{2}-\varepsilon_{1}-2 \varepsilon_{2}\right) \delta_{2}\right]}{9\left(\varepsilon_{1} \delta_{1}+\varepsilon_{2} \delta_{2}-1.3\right)^{2}} \\
& \frac{\partial \pi_{2}^{*}}{\partial \delta_{2}}=\frac{-\varepsilon_{2} \delta_{2}^{2}+\left(2 \varepsilon_{1} \delta_{1}-2.6\right) \delta_{2}+\left[206.35-\left(3 \varepsilon_{1}-1\right) \delta_{1}\right] \cdot\left[2.6-2 \varepsilon_{1}-204.35 \varepsilon_{2}+\left(3 \varepsilon_{1} \varepsilon_{2}-\varepsilon_{2}-2 \varepsilon_{1}\right) \delta_{1}\right]}{9\left(\varepsilon_{1} \delta_{1}+\varepsilon_{2} \delta_{2}-1.3\right)^{2}}
\end{aligned}
$$


Combined with the profit function of land port company, this paper adopts the method of numerical simulation to calculate its equilibrium subsidy using MATLAB software. Through multiple simulation results, when $\varepsilon_{1}=0.1$ and $\varepsilon_{2}=0.2$, it is most suitable for the actual situation.

The relationship between the sum of the balanced income of the land port company and the government subsidy is shown in Figure 1.

Figure 1 shows that the balanced income of land port companies does not continue to increase with the increase of local government subsidies. The total revenue of the two land port companies reached the largest when $\delta_{1}=4.3$ and $\delta_{2}=5$ (i.e., the $\delta_{1}$ and $\delta_{2}$ corresponding to the highest point of the red part in the figure), and the revenue is about $0.7 \times 10^{5} \$ / F E U$. Correspondingly, there is the largest equilibrium income between the land port company (Xi'an) and the land port company (Zhengzhou). Then we calculated the government subsidy of each CR Express in the theory. The subsidy result is shown in Table 2.

In the actual operation of CR Express, the subsidy amount of each train in Xi'an is about $1.23 \times 10^{5}$ dollars, and Zhengzhou local government subsidizes land port company by land plus fund subsidy, and the subsidies up to about 8.4 $\times 10^{8}$ dollars. This is a large gap from the subsidy amount of $1.56 \times 10^{6}$ dollars received by Zhengzhou train. The local government subsidy of Zhengzhou is obviously larger than the balanced subsidy when the interests are maximized. In the long run, it will not be conducive to the normal operation of land port company. Comparatively, the subsidy policy of Xi'an at this stage is still within a reasonable range. This is conducive to the healthy and orderly development of the train for the local government and the land port companies operating the CR Express.

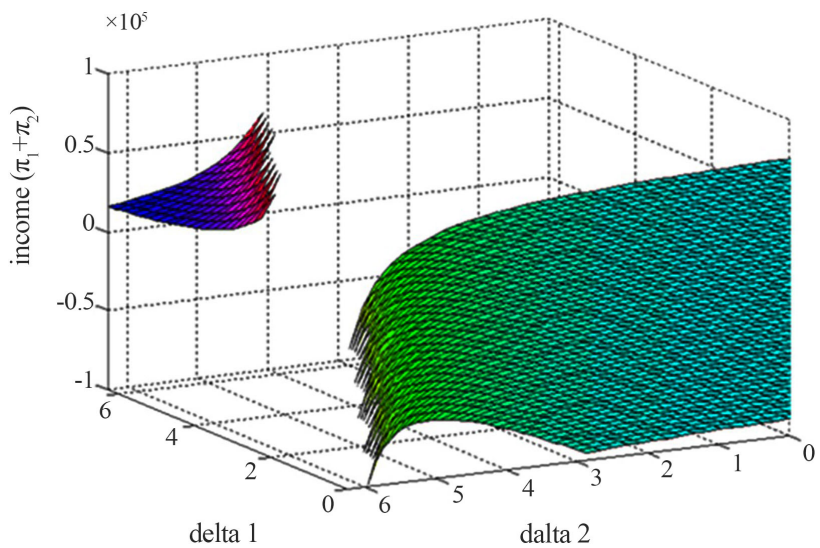

Figure 1. The relationship between government subsidy and the balanced income of land port companies.

Table 2. Reference value of balanced subsidy.

\begin{tabular}{cccc}
\hline Origin city & $\delta_{i}(\$ /$ FEU $\cdot \mathrm{km})$ & Distance $(\mathrm{km})$ & Total subsidy $(\$ /$ train $)$ \\
\hline Xi'an & 4.3 & 7117 & $4.3 \times 41 \times 7117=1.28 \times 10^{6}$ \\
Zhengzhou & 5 & 7628 & $5 \times 41 \times 7628=1.56 \times 10^{6}$ \\
\hline
\end{tabular}




\section{Conclusion}

In order to solve the problems of insufficient supply and disorderly competition, we construct Hotelling model which is in line with the characteristics of the development of CR Express from the aspects of consignor's utility and land port company's revenue. Then the equilibrium price, market share and revenue of land port company are solved, and the optimal local government subsidy under equilibrium condition is analyzed. The results show that when the subsidy amount of each train in Xi'an is about $1.28 \times 10^{6}$ dollars and Zhengzhou is about $1.56 \times 10^{6}$ dollars, the revenue of land port company can be maximized and the financial pressure can be reduced at the same time, thereby relieving the phenomenon of disordered competition.

Based on the characteristics of the development of CR Express, and considering the network externality, the terminal transportation cost of consignors, local government subsidy, and indirect subsidy to consignors, we analyze the relationship between the local government subsidy and the equilibrium price, equilibrium market share and equilibrium income of the land port company, then find out the local government equilibrium subsidy that can meet the maximum income under the equilibrium income. However, there is no comprehensive analysis of the relationship between coefficient of subsidy from land port company to consignor and government subsidy. In the follow-up study, we can consider the impact of different subsidies to consignors on the revenue of land port company more comprehensively, thereby analyzing the balanced subsidy of the local government.

\section{Conflicts of Interest}

The author declares no conflicts of interest regarding the publication of this paper.

\section{References}

He, H. W. (2016). Key Challenge and Countermeasures with Railway Accessibility along the Silk Road. Engineering, 2, 288-291. https://doi.org/10.1016/J.ENG.2016.03.017

Le, W., Chen, N., Cao, C. F., \& Zhang, C. (2018). The Hotelling Game Theory of Port Z's Iron Ore Business. Journal of Wuhan University of Technology (Transportation Science \& Engineering), 42, 497-501. (In Chinese)

Li, S. Q., Lang, M. X., Yu, X. Q., Zhang, M. Y., Jiang, M. H., Tsai, S. B., Wang, C. K., \& Bian, F. (2019). A Sustainable Transport Competitiveness Analysis of the China Railway Express in the Context of the Belt and Road Initiative. Sustainability, 11, 1-30. https://doi.org/10.3390/su11102896

Ma, B. (2018). China Railway Express to Europe: Developments, Problems and Solutions. International Studies, No. 6, 72-86. (In Chinese)

Wang, C. P., Nan, G. F., Li, M. Q., \& Kou, J. S. (2016). Optimal Pricing for Information Goods and Complementary Services in Duopoly Markets. Journal of Management Sciences in China, 19, 92-106. (In Chinese)

Wang, Y. K. (2015). Status, Problems, Suggestions on Development of Sino-Europe Block 
Trains. China Transportation Review, 37, 70-75+89. (In Chinese)

Wang, Z. D. (2018). Main Features and Problems of China Railway Express in 2017 and Suggestions for Development of China Railway Express in 2018. New Silk Road Horizon, No. 2, 31-36. (In Chinese)

Xu, B., \& Zhu, D. L. (2007). Extended Hotelling Model with Network Externality. Journal of Management Sciences in China, No. 1, 9-17.

Yang, D., Pan, K., \& Wang, S. A. (2018). On Service Network Improvement for Shipping Lines under the One Belt One Road Initiative of China. Transportation Research Part E: Logistics and Transportation Review, 117, 82-95. https://doi.org/10.1016/j.tre.2017.07.003

Zhang, L. M. (2018a). Study on the Price Competition among China Railway Express Firms Based on the Extended Hotelling Model. Beijing: Beijing Jiaotong University. (In Chinese)

Zhang, N. (2018b). The "One Belt and One Road" Initiative and China-Europe Train: Issues and Prospects. Academic Journal of Russian Studies, 8, 90-104. (In Chinese)

Zhao, L. J., Zhao, Y., Hu, Q. M., Li, H. Y., \& Stoeter, J. (2018). Evaluation of Consolidation Center Cargo Capacity and Locations for China Railway Express. Transportation Research Part E: Logistics and Transportation Review, 117, 58-81. https://doi.org/10.1016/j.tre.2017.09.007

Zhu, D. L., Yang, H., Li, C. M. et al. (2014). Properties of the Multiclass Traffic Network Equilibria under a Tradable Credit Scheme. Transportation Science, 49, 519-534.

https://doi.org/10.1287/trsc.2013.0508 